Article

\title{
Optimization of X-ray Tube Voltage to Improve the Precision of Two Phase Flow Meters Used in Petroleum Industry
}

\author{
Abdullah K. Alanazi ${ }^{1}\left(\mathbb{D}\right.$, Seyed Mehdi Alizadeh ${ }^{2}$, Karina Shamilyevna Nurgalieva ${ }^{3}$ (D), \\ John William Grimaldo Guerrero ${ }^{4, * \mathbb{D}}$, Hala M. Abo-Dief ${ }^{1}$, Ehsan Eftekhari-Zadeh ${ }^{5, * \mathbb{D}}$, Ehsan Nazemi ${ }^{6} \mathbb{D}$ \\ and Igor M. Narozhnyy ${ }^{7}$
}

check for updates

Citation: Alanazi, A.K.; Alizadeh, S.M.; Nurgalieva, K.S.; Grimaldo Guerrero, J.W.; Abo-Dief, H.M.; Eftekhari-Zadeh, E.; Nazemi, E.; Narozhnyy, I.M. Optimization of $X$-ray Tube Voltage to Improve the Precision of Two Phase Flow Meters Used in Petroleum Industry. Sustainability 2021, 13, 13622. https:/ / doi.org/10.3390/su132413622

Academic Editor: Sławomir Francik

Received: 18 November 2021 Accepted: 6 December 2021 Published: 9 December 2021

Publisher's Note: MDPI stays neutral with regard to jurisdictional claims in published maps and institutional affiliations.

Copyright: (c) 2021 by the authors. Licensee MDPI, Basel, Switzerland. This article is an open access article distributed under the terms and conditions of the Creative Commons Attribution (CC BY) license (https:/ / creativecommons.org/licenses/by/ $4.0 /)$.
1 Department of Chemistry, Faculty of Science, Taif University, P.O. Box 11099, Taif 21944, Saudi Arabia; aalanaz4@tu.edu.sa (A.K.A.); h.abodeif@tu.edu.sa (H.M.A.-D.)

2 Petroleum Engineering Department, Australian College of Kuwait, West Mishref 13015, Kuwait; s.alizadeh@ack.edu.kw

3 Department of Development and Operation of Oil and Gas Fields, Saint-Petersburg Mining University, 199106 Saint-Petersburg, Russia; khaibullina_k@mail.ru

4 Department of Energy, Universidad de la Costa, Barranquilla 080001, Colombia

5 Institute of Optics and Quantum Electronics, Friedrich-Schiller-University Jena, Max-Wien-Platz 1, 07743 Jena, Germany

6 Imec-Vision Laboratory, Department of Physics, University of Antwerp, 2610 Antwerp, Belgium; ehsan.nazemi@uantwerpen.be

7 Department of Commercialization of Intellectual Activity Resultse Center for Technology Transfer, Mining Oil and Gas Department, RUDN University, 117198 Moscow, Russia; narozhnyy-im@rudn.ru

* Correspondence: jgrimald1@cuc.edu.co (J.W.G.G.); e.eftekharizadeh@uni-jena.de (E.E.-Z.)

\begin{abstract}
To the best knowledge of the authors, in all the former studies, a fixed value of X-ray tube voltage has been used for investigating gas-liquid two-phase flow characteristics, while the energy of emitted X-ray radiations that depends on the tube voltage can significantly affect the measurement precision of the system. The purpose of present study is to find the optimum tube voltage to increase the accuracy and efficiency of an intelligent $X$-ray radiation-based two-phase flow meter. The detection system consists of an industrial X-ray tube and one detector located on either side of a steel pipe. Tube voltages in the range of $125-300 \mathrm{kV}$ with a step of $25 \mathrm{kV}$ were investigated. For each tube voltage, different gas volume percentages (GVPs) in the range of $10-90 \%$ with a step of $5 \%$ were modeled. A feature extraction method was performed on the output signals of the detector in every case, and the obtained matrixes were applied to the designed radial basis function neural networks (RBFNNs). The desired output of the networks was GVP. The precision of the networks in every voltage and every number of neurons in the hidden layer were obtained. The results showed that $225 \mathrm{kV}$ tube voltage is the optimum voltage for this purpose. The obtained mean absolute error $(M A E)$ for this case is less than 0.05 , which demonstrates the very high precision of the metering system with an optimum $\mathrm{X}$-ray tube voltage.
\end{abstract}

Keywords: tube voltage optimization; artificial intelligence; X-ray; two-phase flow; GVP; sustainable technology

\section{Introduction}

Two-phase flow is receiving increasing attention from researchers in different study fields. The GVP and flow regime are the most important parameters utilized to measure gas-liquid two-phase flow characteristics. There are a few sustainable nondestructive techniques such as electrical capacitance [1], electromagnetic [2], ultrasonic [3], and gamma [4]/X-ray [5]/neutron [6] radiation attenuation to determine the mentioned parameters in two-phase flows.

In the last few decades, numerous researchers have conducted different investigations on measuring characteristics of two-phase flows using X-ray radiation. In 1969, G.F. Hewitt 
and D.N. Roberts used an X-ray tube with voltage of $100 \mathrm{kV}$ and conventional X-ray radiography film to investigate flow patterns in a vertical upwards flow of air-water mixtures [7]. In 1975, O. Jone and N. Zuber used a Phillips Norelco X-ray system with tube voltage of $50 \mathrm{kV}$ to investigate various flow patterns of slug, bubbly, and annular in an air-water two-phase flow inside a rectangular channel [8]. In 1999, G.D. Harvel et al. developed a high-speed X-ray CT system for measuring the GVP distribution for bubbly and slug flow patterns inside a vertical pipe [9]. Their system consisted of an X-ray tube with a tube voltage of $70 \mathrm{kV}$ located in front of an array of $\mathrm{CdWO}_{4}$ scintillator detectors. In 2010, F. Fischer and U. Hampel proposed a fast response system with frame rates of 1000 images per second for determining gas-water two-phase flows [10]. Their system included an X-ray tube and 240 CZT detectors positioned in a circular array. In 2018, Song and Liu established a compact X-ray system including an X-ray tube with tube voltage of $50 \mathrm{kV}$ and an array of detector for determining GVF and liquid phase's velocity in a slug and bubbly two-phase flow [11]. In 2020, M. Roshani et al. proposed an intelligent approach using an X-ray tube with a tube voltage of $150 \mathrm{kV}$ and an artificial neural network (ANN) to predict GVF in stratified and annular flow regimes of a gas-liquid two-phase flow [12]. They also used the same system in another separate study in order to determine type of flow regime in a two-phase flow [13]. In recent years, a large number of studies have been also performed on X-ray imaging of two-phase flows. S.A. Mäkiharju et al. proposed a two-dimensional $\mathrm{X}$-ray system with an imaging rate of $1 \mathrm{kHz}$ to determine the void fraction distribution in gas-liquid two-phase flows [14]. Their results showed that the proposed system has a good precision for void fractions above $5 \%$. A. Tekawade et al. developed an in situ 3D synchrotron X-ray visualization system to image the two-phase flow inside a diesel injection nozzle [15]. Heindel presented a review of the current status of X-ray multiphase flow visualization methods [16].

As described in the literature review, in all the previous studies, a fixed value of tube voltage was used for investigating gas-liquid two-phase flows, while energy of emitted $\mathrm{X}$-ray radiations that depend on the tube voltage can affect measurement precision of the system. In other words, once energy of X-ray radiations are less than an optimum value, they cannot penetrate well through the pipe and flow, which consequently causes reduction in measurement precision of the system. On the other hand, once the energy of $\mathrm{X}$-ray radiations is higher than an optimum value, the contrast between the gas and liquid phase is decreased, which again leads to the system's measurement precision reduction. The purpose of the present study is finding an optimum tube voltage in order to increase the measurement precision and efficiency of the X-ray radiation based two-phase flow meters. Details of the proposed system and optimization procedure are described in the following sections.

\section{Materials and Method}

\subsection{Detection System}

The investigations in the present study were performed using Monte Carlo N-Particle code (MCNPX). MCNPX code can be implemented as a powerful tool for simulating and transporting various radiations such as electrons, photons, and neutrons, etc. [17]. In has been widely used for modeling various radiation-based instruments [18-24]. As depicted in in Figure 1, the main components of the modeled detection system are one common commercial X-ray source and one sodium iodide detector. An electron source was defined inside the vacuum chamber of tube as the electron filament. A tungsten slab with an orientation of $20^{\circ}$ was located inside the tube and in front of the electron source. The energy of emitted electrons from the source was changed from 125 to $300 \mathrm{keV}$ with a step of $25 \mathrm{keV}$ to investigate the optimum tube voltage for X-ray radiation-based two-phase flow meters. The reason of choosing $125 \mathrm{keV}$ for the lower energy limit is that the generated X-rays with energies lower than this limit cannot penetrate well through the steel pipe and therefore would not be useful to be investigated in this study. It must be noted that, in all the simulations, the maximum allowed number of particles (NPS) in the MCNPX code, 
2.1 billion, was used for the photon source. Using the mentioned NPS, for tube voltages in the range of $125 \mathrm{kV}$ or more, a statistical error of less than $1 \%$ was achieved, which means that the obtained results are trustable [17]. For tube voltage of $100 \mathrm{kV}$ or less, the obtained statistical error was about $40 \%$ or more, which means that there was too much attenuation for X-ray radiations (in other words, there was not enough penetration) and consequently enough photons did not reach the detector.
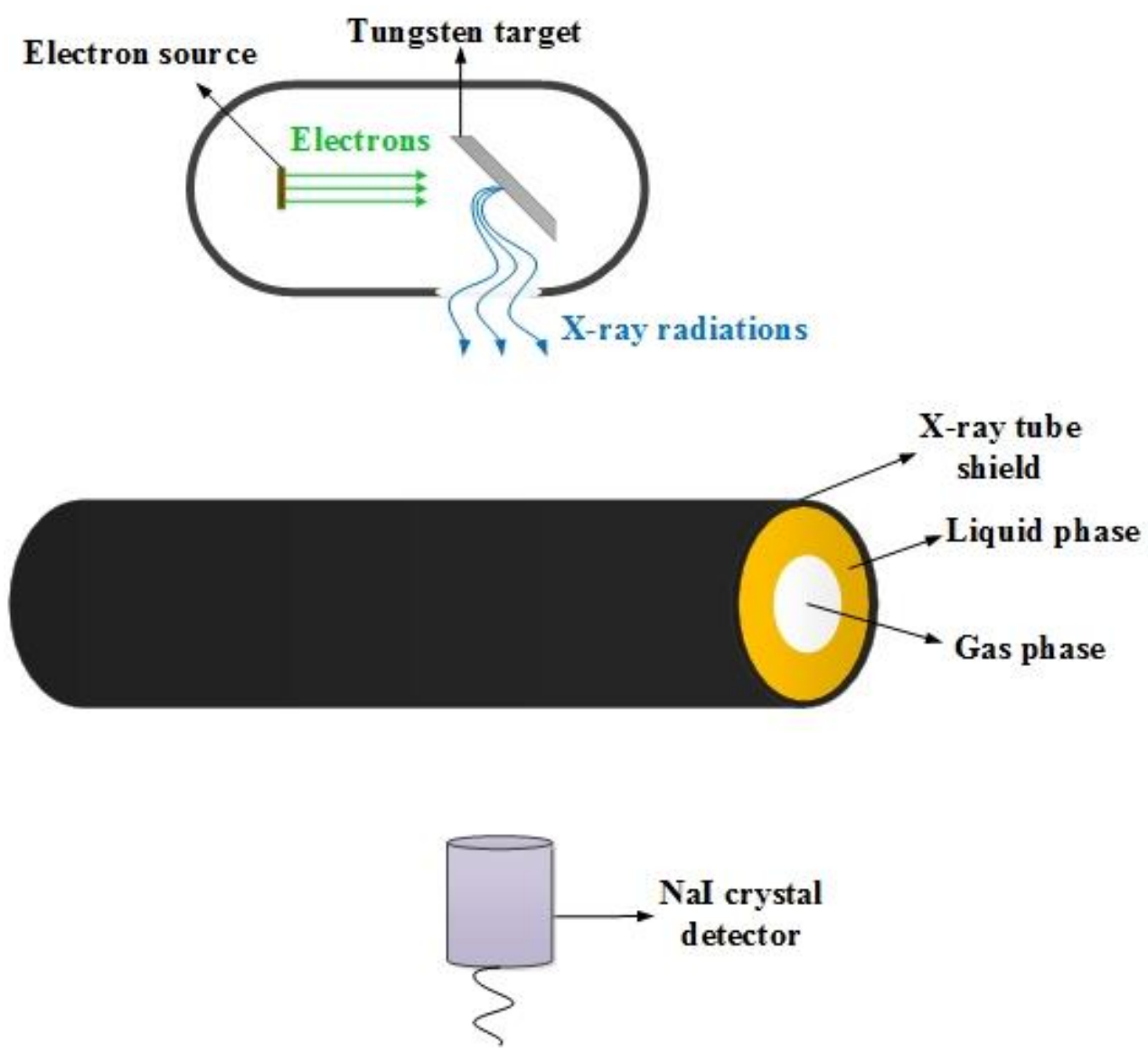

Figure 1. Main components of the modeled detection system.

Additionally, the reason for choosing $300 \mathrm{keV}$ as the upper limit is that the maximum voltage of the commercial industrial X-ray tubes does not go higher than $300 \mathrm{kV}$. It is worth mentioning that the energy of emitted electrons from the filament is almost the same as the X-ray tube voltage. In fact, the emitted electrons from the filament are accelerated inside the vacuum chamber under a high electrical potential difference and then smashed into the tungsten target. Approximately one percent of the electron's energy is radiated as X-rays and comes out from the tube's window. The rest of energy is converted to heat through the target.

The generated $X$-ray radiations form a spectrum energy with a maximum value equal to the tube voltage. The energy spectra of generated $X$-rays in this study for tube voltages of $125,150,175,200,225,250,275$, and $300 \mathrm{kV}$ are shown in Figure 2 . For the sake of a better comparison, every energy spectrum was normalized to its sum of intensity. L-shell (with energy of $8.5 \mathrm{keV}$ ) and K-shell (2 peaks with energies of 59.5 and $67.5 \mathrm{keV}$ ) X-ray characteristic peaks of tungsten are clearly seen in Figure 2 for all the tube voltages. It can be also seen that, by increasing the tube voltage, the intensity ratio of two K-shell peaks to the L-shell peak is increased. 


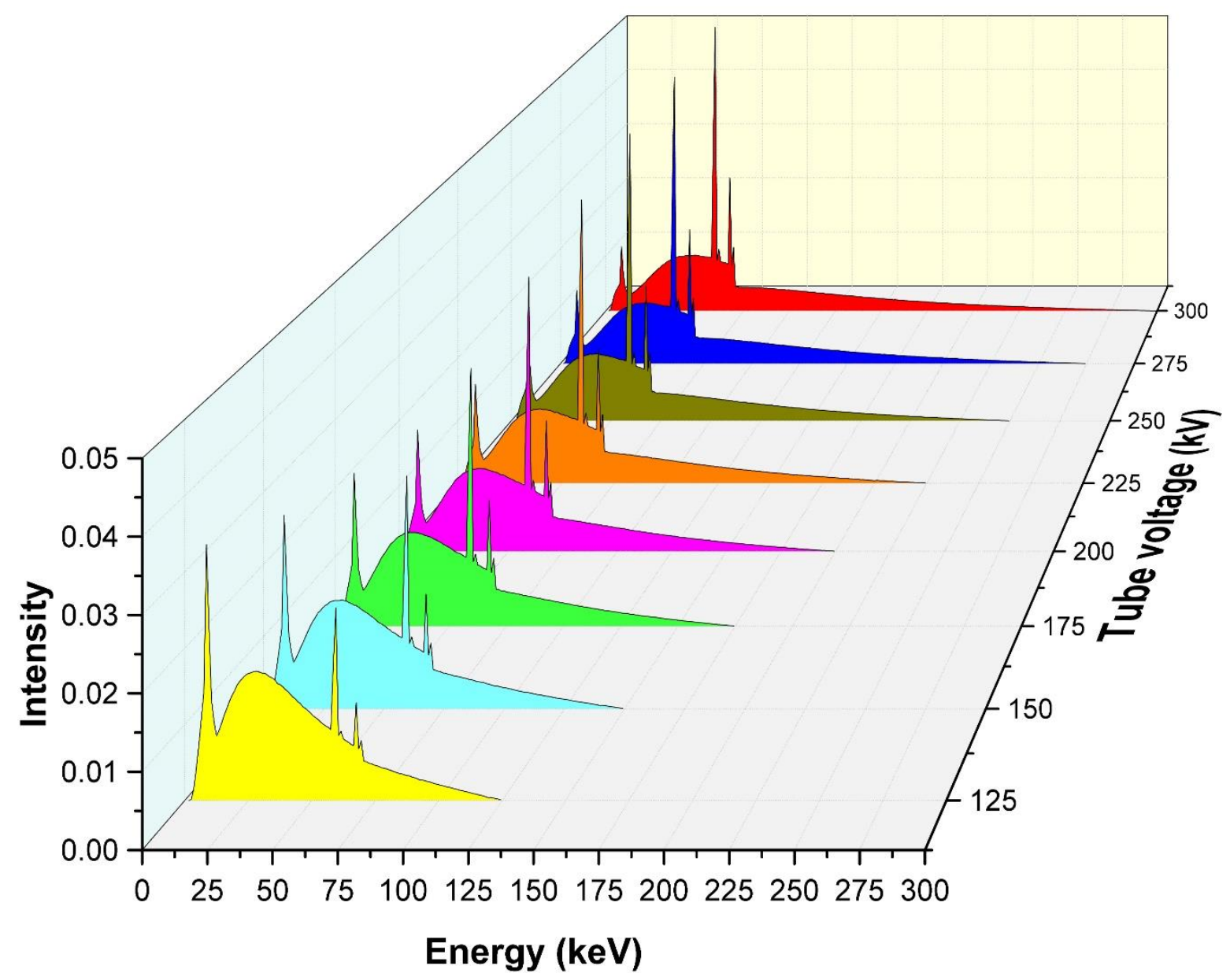

Figure 2. The energy spectra of generated X-ray radiations in this study for tube voltages of 125, 150, 175, 200, 225, 250, 275, and $300 \mathrm{kV}$.

A steel pipe with an inner diameter of 3 inches, which is a typical size in the petroleum industry, was considered in the simulations. The thickness of mentioned pipe is $0.5 \mathrm{~cm}$. A liquid-gas two-phase flow with annular pattern was also modeled inside the pipe. Air and gasoil with densities of 1.25 and $826 \mathrm{~kg} / \mathrm{m}^{3}$ were used as the gas and liquid phases, respectively. The following mathematical equation was used for modeling various gas volume percentages inside the pipe:

$$
\operatorname{GVP}(\%)=\frac{\pi r_{g}^{2}}{\pi r_{p}^{2}} \times 100=\frac{r_{g}^{2}}{r_{p}^{2}} \times 100
$$

where $r_{p}, r_{g}$, and GVP are inner radius of the steel pipe, radius of the gas phase in core of the pipe, and GVP is the gas volume percentage, respectively. $r_{p}$ is a fixed parameter in all the simulations. For every specified GVP, the gas phase's radius was calculated using Equation (1). For each tube voltage, different GVPs in the range of $10-90 \%$ with a step of $5 \%$ were modeled (17 totally, 136 simulations).

\subsection{X-ray Tube Voltage Optimization Procedure}

In order to optimize the voltage of the $\mathrm{X}$-ray tube, several voltages were considered and simulated using MCNP-X code. Voltages 125, 150, 175, 200, 225, 250, 275, and 300 were considered the X-ray tube voltage and, in every voltage, several simulations in different volume fractions were performed. In fact, in every voltage, the gas volume fraction varied from 10 to 90 by steps of five. These volumes were considered as the GVPs of a typical annular two-phase flow. In every case (every voltage and every $G V P$ ), the output spectrum 
of $\mathrm{NaI}(\mathrm{Tl})$ detector was obtained and, accordingly, all of the required data were generated. In order to achieve the efficiency of the presented system in different voltages, the radial basis function neural network (RBFNN), which uses matrix inverse, was selected. RBFNN is a useful type of ANN. RBF can be used to approximate functions [25]. Equations (2)-(4) show the algorithm of a typical RBFNN [25].

$$
\begin{gathered}
\text { output }=\sum(\text { weight } \times \text { input })+\text { bias } \\
y_{m}=e^{\left(-\frac{\left\|x-v_{m}\right\|^{2}}{2 \sigma_{m}^{2}}\right)} \\
z_{j}=\sum_{m=1}^{M} u_{m j} y_{m}+b_{j}
\end{gathered}
$$

where $x$ is the feature vector, $v$ is the center position, $\sigma$ is the spread, $z_{j}$ is the output prediction from the $j$ th node of the output layer, $u_{m j}$ is weights, and $b_{j}$ is bias. It is worth mentioning that, in the past few decades, various advanced computational approaches, e.g., finite element, numerical linear algebra, statistics, numerical analysis, tensor analysis, and artificial intelligence, have been applied in various fields of study such as chemical engineering [26-29], electrical and computer engineering [30-37], civil engineering [38-40], mechanical engineering [41-55], petroleum engineering [56-69], environmental engineering [70,71], biomedical engineering [72-76], mathematics [77-83], etc.

The output signal (detector output spectrum) in each case was divided into several features. In fact, the continuous spectrum was transformed to discrete inputs for the training of the neural network. In this regard, each $1 \mathrm{keV}$ was considered as one feature so the output spectrum in tube voltage of 125 and $275 \mathrm{kV}$ was converted to 125 and 275 features, respectively. These features are extracted from the output signals and applied to the RBFNN for measuring the GVP.

For instance, the output signals related to $10 \%$ GVP and $125 \mathrm{kV}$ of tube voltage with the energy of 0 to $125 \mathrm{keV}$ were divided into 125 equal sections, and these sections were applied to RBFNN. This feature extraction method and applying procedure for a typical sample $(10 \%$ GVP and $125 \mathrm{kV}$ tube voltage) is shown in Figure 3.

RBFNN with different number of neurons in the hidden layer was used to measure the GVP of the considered annular two-phase flow. This kind of network can recognize the properties of complex and nonlinear systems such as multi-phase flows. For solving this problem, MATLAB software (version 8.1.0.604, MathWorks: Natick, MA, USA) was used to train the networks. A total of $70 \%$ were used for training, and the rest of them were used for testing. In fact, 96 samples were used for training the networks. For designing the architectures, the mean squared error goal and spread of radial basis functions were considered 0 and 1 , respectively. Additionally, every $X$-ray tube voltage was tested in every possible neuron number in the hidden layer. In the coding, the "newrb" command was used. This command adds neurons to the hidden layer of the network until it meets the specified mean squared error goal.

\section{Results and Discussion}

As an example, recorded X-ray energy spectra in the detector for tube voltage of $150 \mathrm{kV}$ and gas volume percentages in the range of 10-90\% are depicted in Figure 4 . This figure indicates that almost all the $X$-ray radiations with energy lower than $70 \mathrm{keV}$ were fully absorbed inside the pipe. This figure also shows a regular incremental manner in the intensity of X-ray spectra once the gas volume percentage is increased. 


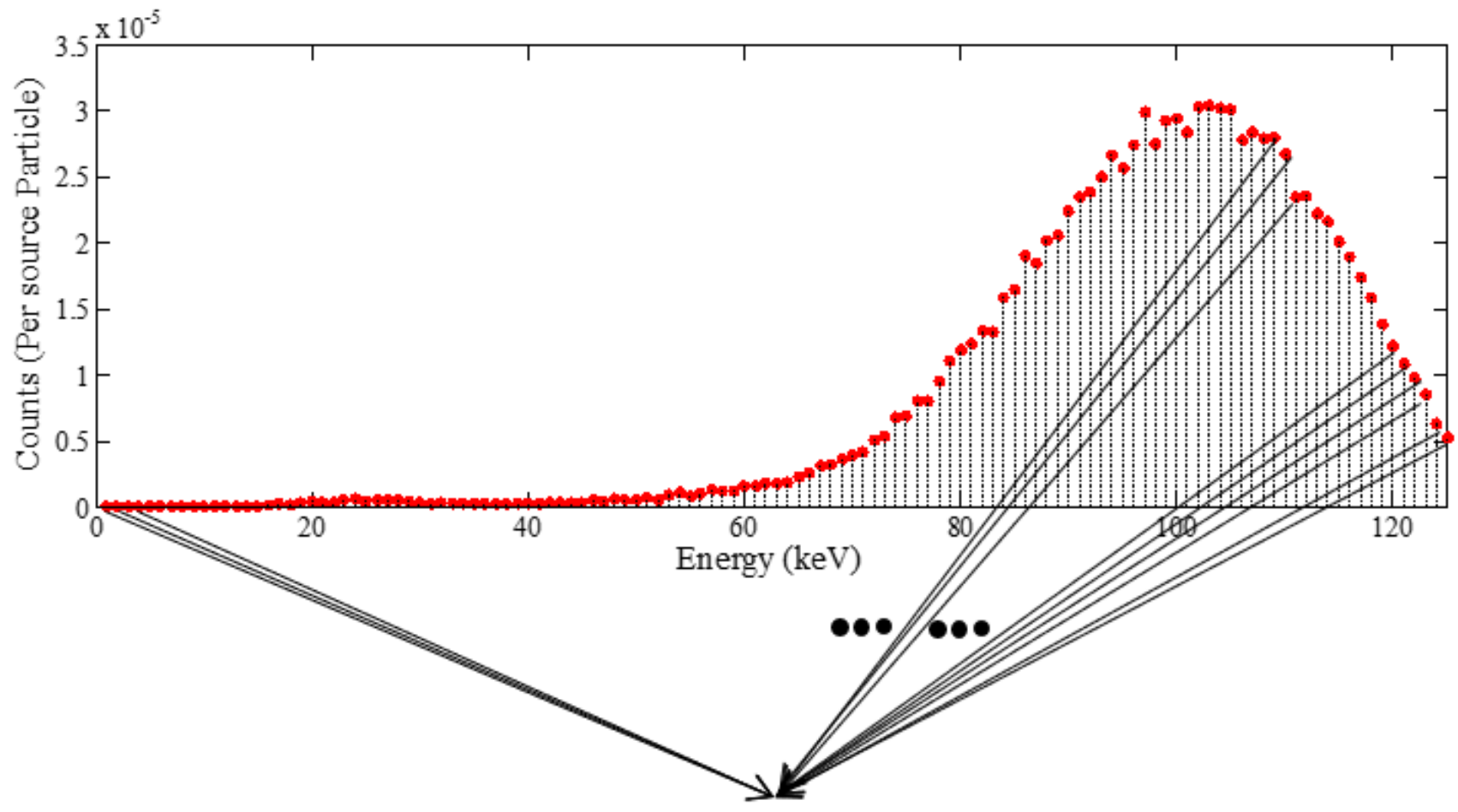

\section{The continuous spectrum is transformed to 125 discrete inputs}

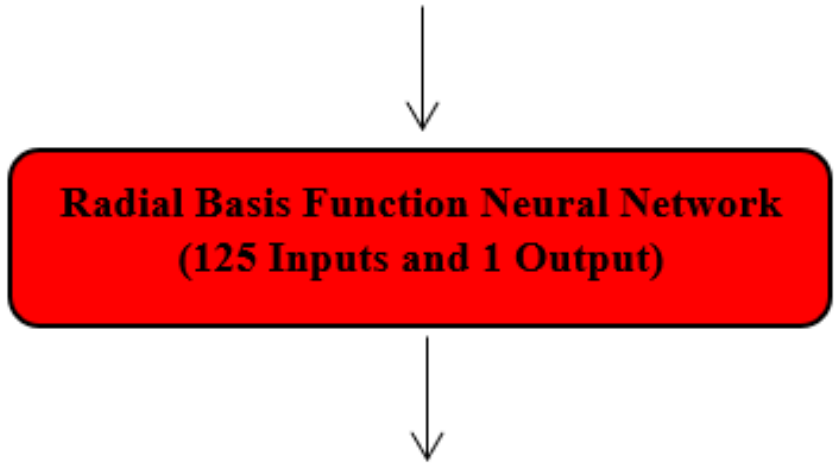

\section{Void Fraction}

Figure 3. Applying the 125 extracted features to the RBFNN.

Comparison of recorded spectra in the detector once the gas volume percentage is kept fixed at a value of $80 \%$ and the tube voltage is increased from 125 to $300 \mathrm{kV}$ are shown in Figure 5. As it is observed, although the intensity of X-ray spectra are increased by increasing the tube voltage, the intensity difference between two successive tube voltages is reduced. 


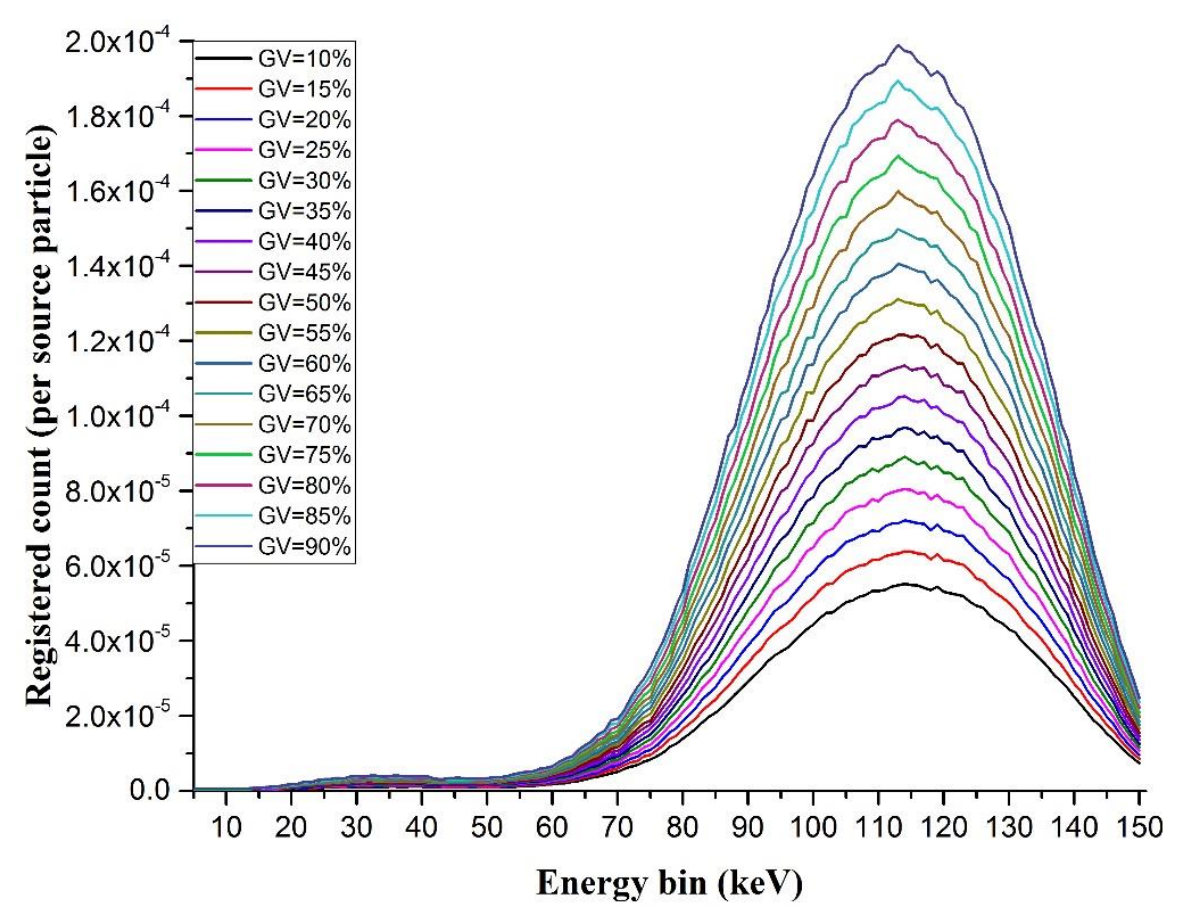

Figure 4. Recorded X-ray energy spectra in the detector for tube voltage of $150 \mathrm{kV}$ and gas volume percentages in the range of $10-90 \%$.

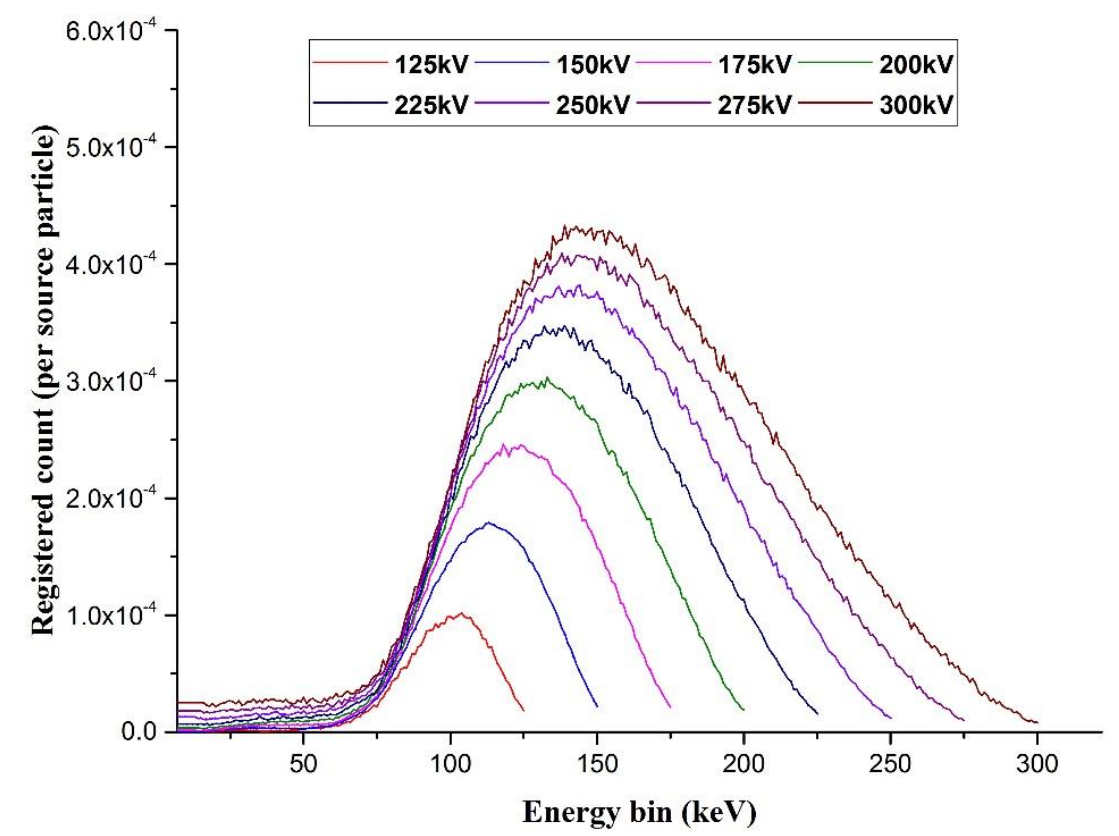

Figure 5. Recorded spectra in the detector once the gas volume percentage is kept fixed at a value of $80 \%$, and the tube voltage is increased from 125 to $300 \mathrm{kV}$.

The mean absolute error $(M A E)$ and mean relative error percentage $(M R E \%)$ were used to compare different $X$-ray tube voltages efficiency and find the optimized condition. These errors are calculated as follows:

$$
M A E=\frac{1}{N} \sum_{i=1}^{N} \mid X_{i}(\text { Real })-X_{i}(\text { Measuring }) \mid
$$




$$
M R E \%=100 \times \frac{1}{N} \sum_{i=1}^{N}\left|\frac{X_{i}(\text { Real })-X_{i}(\text { Measuring })}{X_{i}(\text { Real })}\right|
$$

where $N$ is the number of data and ' $X$ (Real)' and ' $X$ (Measuring)' apply for simulated data and measured data, respectively. The measured data has been obtained by ray-tracing and applying it to the presented neural networks and is considered a measured output. This value should be near the desired output, which has been considered as the real output. Therefore, the low difference between these two parameters shows the precision of the presented method. The results of obtaining GVP in an annular two-phase flow for different $X$-ray tube voltages and different number of neurons in hidden layer of considered RBFNN were tabulated in Table 1. In this table, MAE and MRE of both train and test sets were shown. It is clear that, by increasing the number of neurons in the hidden layer in each voltage, the $M A E$ train and $M R E$ train will be decreased. In the cases with very low train errors and considerable test errors, the measuring system has been encountered with an overfitting problem. In fact, a structure with minimum $M A E$ test and $M R E$ test and also lower $M A E$ train and $M R E$ train is the best structure, and its voltage is the optimum point.

Table 1. The achieved results of obtaining GVP in an annular two-phase flow for different X-ray tube voltages and different number of neurons in the hidden layer of RBFNN.

\begin{tabular}{|c|c|c|c|c|c|c|c|c|c|c|c|}
\hline Tube Voltage & & 1 Neuron & 2 Neurons & 3 Neurons & 4 Neurons & 5 Neurons & 6 Neurons & 7 Neurons & 8 Neurons & 9 Neurons & 10 Neurons \\
\hline \multirow{4}{*}{125} & $M A E$ train & 5.106 & 0.21 & 0.114 & 0.105 & 0.102 & 0.102 & 0.084 & 0.04 & 0.036 & 0.03 \\
\hline & MRE $\operatorname{train}(\%)$ & 15.562 & 0.815 & 0.47 & 0.443 & 0.424 & 0.424 & 0.245 & 0.112 & 0.098 & 0.087 \\
\hline & $M A E$ test & 3.852 & 0.148 & 0.096 & 0.132 & 0.144 & 0.145 & 0.111 & 0.088 & 0.087 & 0.074 \\
\hline & MRE test (\%) & 8.022 & 0.398 & 0.151 & 0.239 & 0.275 & 0.279 & 0.291 & 0.28 & 0.272 & 0.228 \\
\hline \multirow{4}{*}{150} & $M A E$ train & 5.223 & 0.146 & 0.143 & 0.085 & 0.068 & 0.045 & 0.032 & 0.014 & 0.007 & 0.002 \\
\hline & $M R E$ train (\%) & 15.977 & 0.657 & 0.624 & 0.44 & 0.338 & 0.142 & 0.069 & 0.036 & 0.021 & 0.006 \\
\hline & MAE test & 3.958 & 0.107 & 0.093 & 0.108 & 0.203 & 0.113 & 0.09 & 0.118 & 0.181 & 0.156 \\
\hline & MRE test $(\%)$ & 8.212 & 0.341 & 0.266 & 0.272 & 0.459 & 0.253 & 0.221 & 0.283 & 0.447 & 0.381 \\
\hline \multirow{4}{*}{175} & $M A E$ train & 5.316 & 0.163 & 0.158 & 0.157 & 0.075 & 0.069 & 0.049 & 0.027 & 0.02 & 0.002 \\
\hline & MRE train (\%) & 16.302 & 0.708 & 0.651 & 0.659 & 0.226 & 0.219 & 0.176 & 0.069 & 0.053 & 0.005 \\
\hline & MAE test & 4.006 & 0.113 & 0.115 & 0.104 & 0.079 & 0.088 & 0.129 & 0.103 & 0.213 & 0.166 \\
\hline & MRE test $(\%)$ & 8.313 & 0.331 & 0.368 & 0.343 & 0.223 & 0.259 & 0.35 & 0.291 & 0.571 & 0.44 \\
\hline \multirow{4}{*}{200} & $M A E$ train & 5.403 & 0.179 & 0.107 & 0.062 & 0.044 & 0.025 & 0.017 & 0.01 & 0.01 & 0.004 \\
\hline & MRE train (\%) & 16.585 & 0.729 & 0.386 & 0.306 & 0.133 & 0.07 & 0.053 & 0.033 & 0.033 & 0.009 \\
\hline & MAE test & 4.075 & 0.111 & 0.148 & 0.16 & 0.095 & 0.094 & 0.103 & 0.102 & 0.105 & 0.074 \\
\hline & MRE test $(\%)$ & 8.426 & 0.342 & 0.379 & 0.43 & 0.24 & 0.22 & 0.237 & 0.243 & 0.249 & 0.174 \\
\hline \multirow{4}{*}{225} & $M A E$ train & 5.458 & 0.165 & 0.156 & 0.138 & 0.04 & 0.041 & 0.034 & 0.019 & 0.005 & 0.002 \\
\hline & MRE train (\%) & 16.769 & 0.733 & 0.672 & 0.639 & 0.16 & 0.153 & 0.118 & 0.057 & 0.011 & 0.006 \\
\hline & MAE test & 4.113 & 0.121 & 0.107 & 0.116 & 0.099 & 0.078 & 0.054 & 0.13 & 0.053 & 0.05 \\
\hline & MRE test $(\%)$ & 8.498 & 0.359 & 0.305 & 0.33 & 0.232 & 0.204 & 0.154 & 0.286 & 0.149 & 0.14 \\
\hline \multirow{4}{*}{250} & $M A E$ train & 5.52 & 0.154 & 0.142 & 0.052 & 0.053 & 0.035 & 0.026 & 0.015 & 0.006 & 0.006 \\
\hline & MRE train (\%) & 16.95 & 0.684 & 0.625 & 0.15 & 0.152 & 0.121 & 0.1 & 0.048 & 0.014 & 0.015 \\
\hline & MAE test & 4.16 & 0.115 & 0.097 & 0.062 & 0.061 & 0.072 & 0.081 & 0.082 & 0.081 & 0.083 \\
\hline & MRE test $(\%)$ & 8.54 & 0.359 & 0.335 & 0.178 & 0.174 & 0.192 & 0.219 & 0.219 & 0.203 & 0.206 \\
\hline \multirow{4}{*}{275} & $M A E$ train & 5.59 & 0.163 & 0.122 & 0.071 & 0.059 & 0.035 & 0.025 & 0.023 & 0.017 & 0.009 \\
\hline & MRE train (\%) & 17.158 & 0.691 & 0.487 & 0.248 & 0.185 & 0.082 & 0.064 & 0.059 & 0.044 & 0.016 \\
\hline & MAE test & 4.194 & 0.14 & 0.133 & 0.081 & 0.069 & 0.075 & 0.115 & 0.105 & 0.091 & 0.101 \\
\hline & MRE test (\%) & 8.608 & 0.413 & 0.393 & 0.211 & 0.16 & 0.158 & 0.287 & 0.254 & 0.19 & 0.229 \\
\hline \multirow{4}{*}{300} & $M A E$ train & 5.637 & 0.18 & 0.151 & 0.114 & 0.094 & 0.07 & 0.039 & 0.021 & 0.009 & 0.007 \\
\hline & MRE train (\%) & 17.347 & 0.755 & 0.59 & 0.517 & 0.313 & 0.172 & 0.097 & 0.043 & 0.03 & 0.0262 \\
\hline & MAE test & 4.224 & 0.159 & 0.15 & 0.15 & 0.08 & 0.15 & 0.066 & 0.076 & 0.064 & 0.107 \\
\hline & MRE test (\%) & 8.66 & 0.462 & 0.407 & 0.42 & 0.21 & 0.317 & 0.139 & 0.159 & 0.133 & 0.224 \\
\hline
\end{tabular}

Two contour graphs for showing both test errors for each case are shown in Figure 6. Additionally, a 3D plot that shows the precision $(=100-M A E)$ of each case is illustrated in Figure 7.

As it can be found from Table 1 and Figures 6 and 7, the optimum tube voltage is $225 \mathrm{kV}$. The top three cases were achieved in this voltage. The best case is $225 \mathrm{kV}$ of X-ray tube voltage and 10 neurons in the hidden layer.

The obtained results for GVP measuring in optimum condition ( $225 \mathrm{kV}$ and 10 neurons) using RBFNN, and the comparisons with the real data are shown for training and testing sets in Figures 8 and 9. Comparing the real data as the target and the measured data as the output, in a regression diagram that shows the relationship between targets and outputs, obtained RMSE errors for every case, and a histogram of obtained errors that shows the distribution of errors have been demonstrated in Figures 8a, 9a and 8b, Figures 9b and 8c, Figures $9 \mathrm{c}$ and $8 d$, Figure $9 d$, respectively. These graphs show the very high precision of the metering system in the optimum condition. 


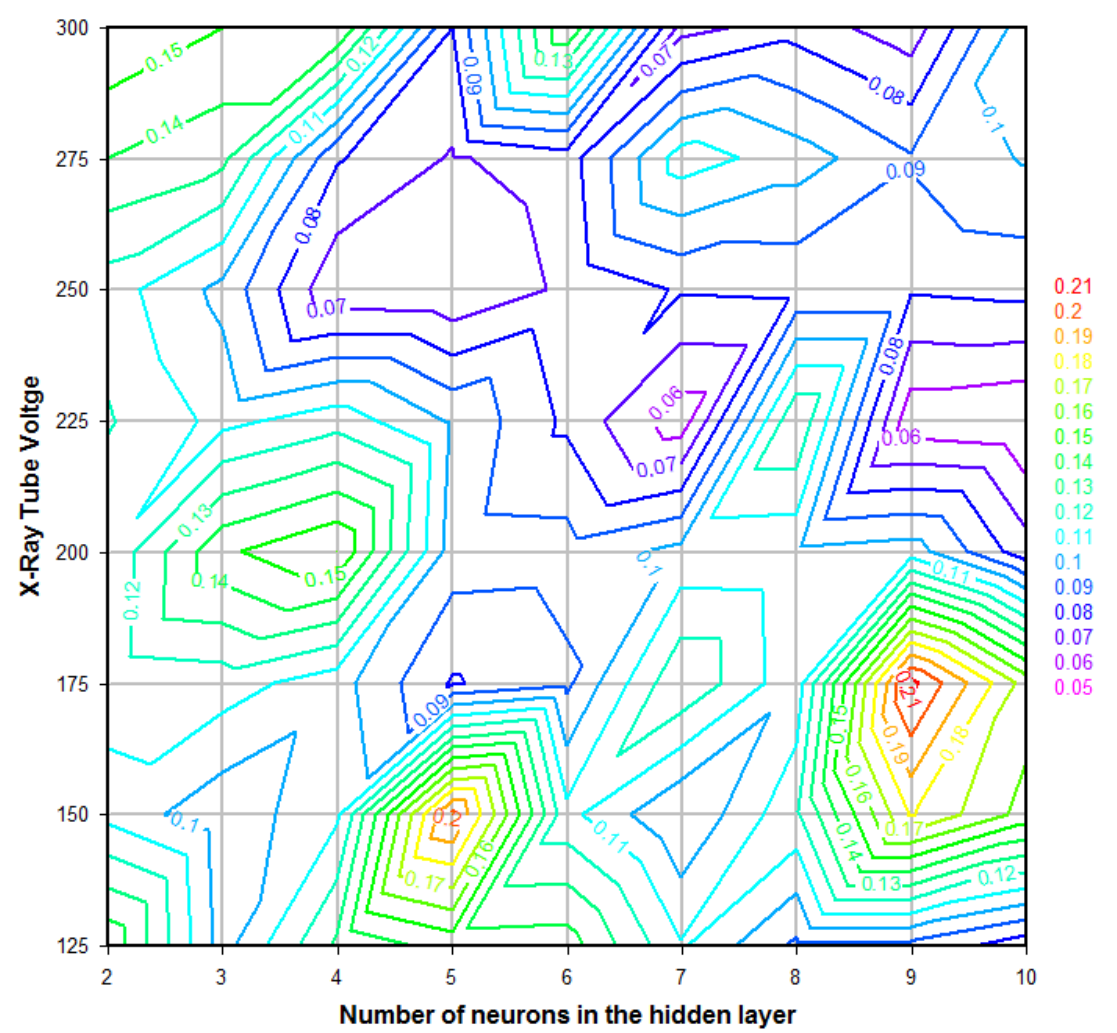

(a)

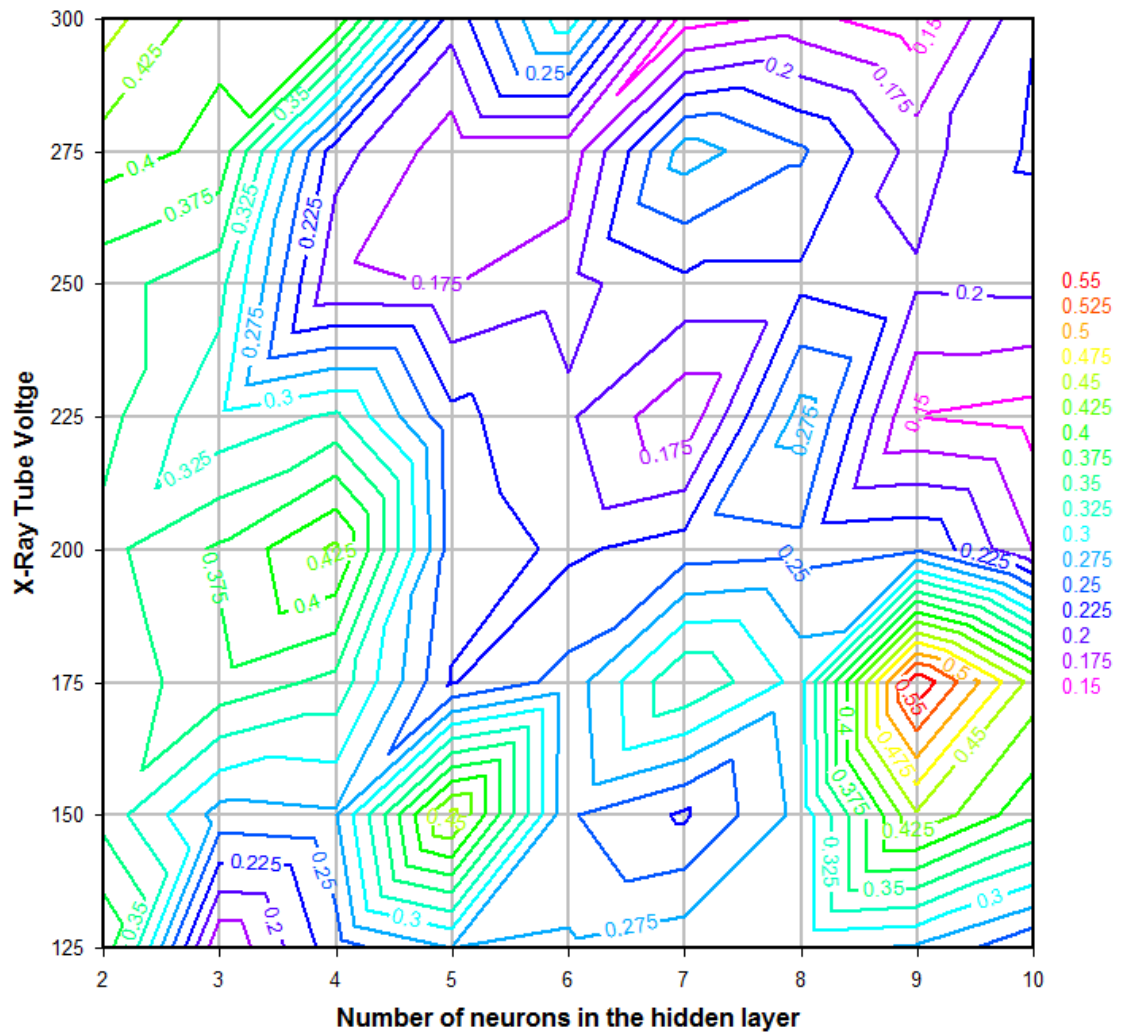

(b)

Figure 6. (a) 'MAE test' and (b) 'MRE test' contour graph for all of the structures. 


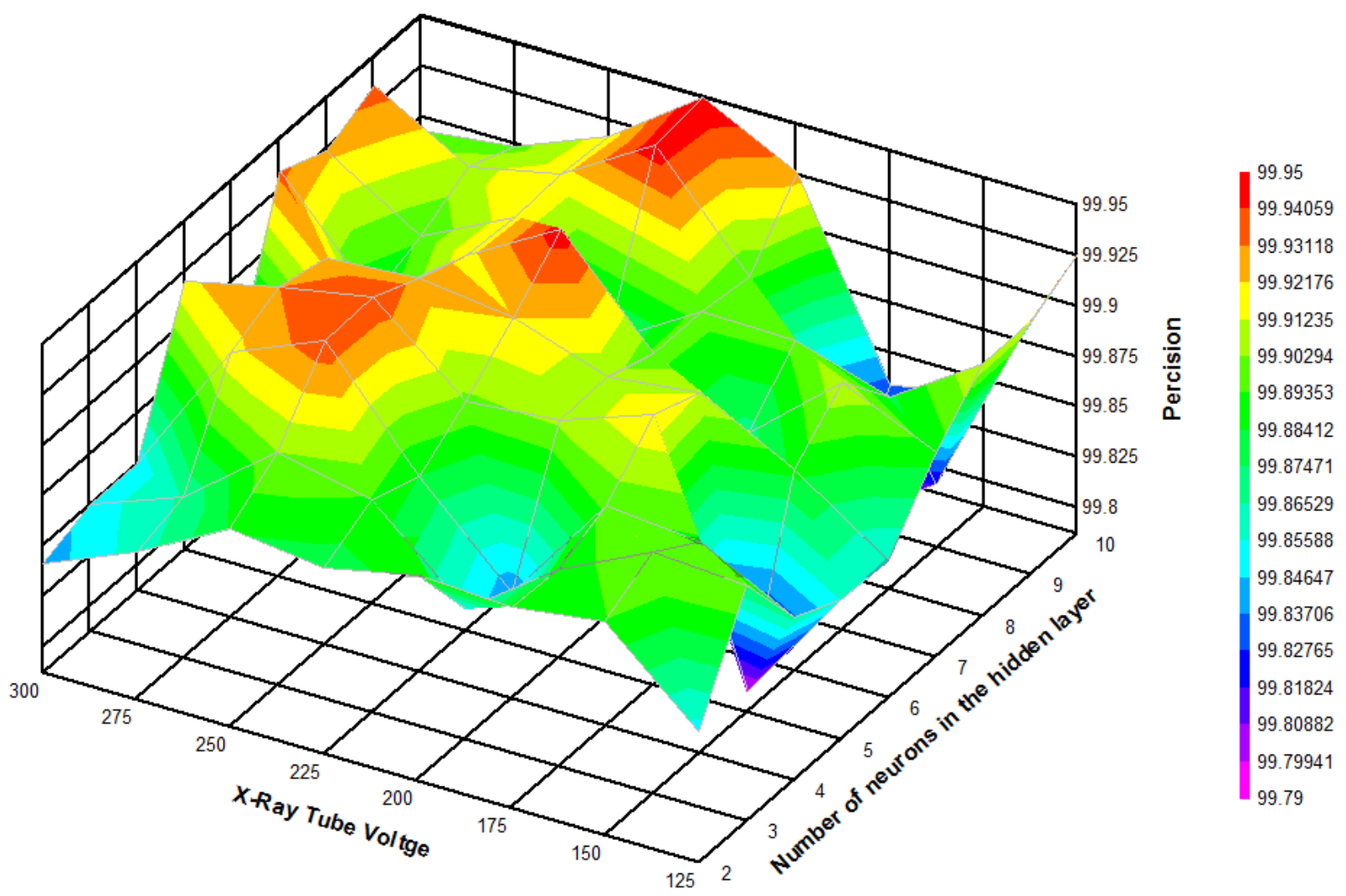

Figure 7. Precision of metering system in every X-ray tube voltage and number of neurons in the hidden layer.
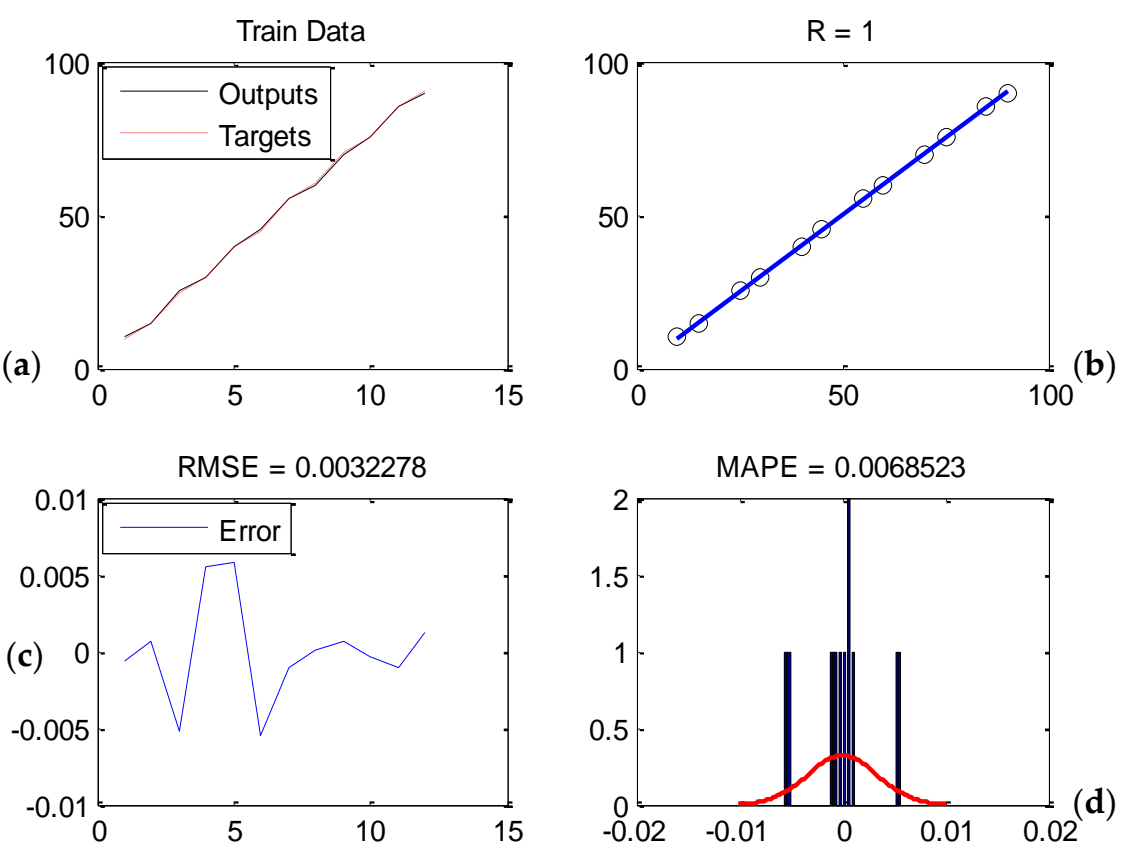

Figure 8. Regression diagram and comparison of real and measured data for train data in the optimum voltage: (a) comparison of real and measured data, (b) regression diagram, (c) obtained RMSE error, and (d) histogram of obtained error. 

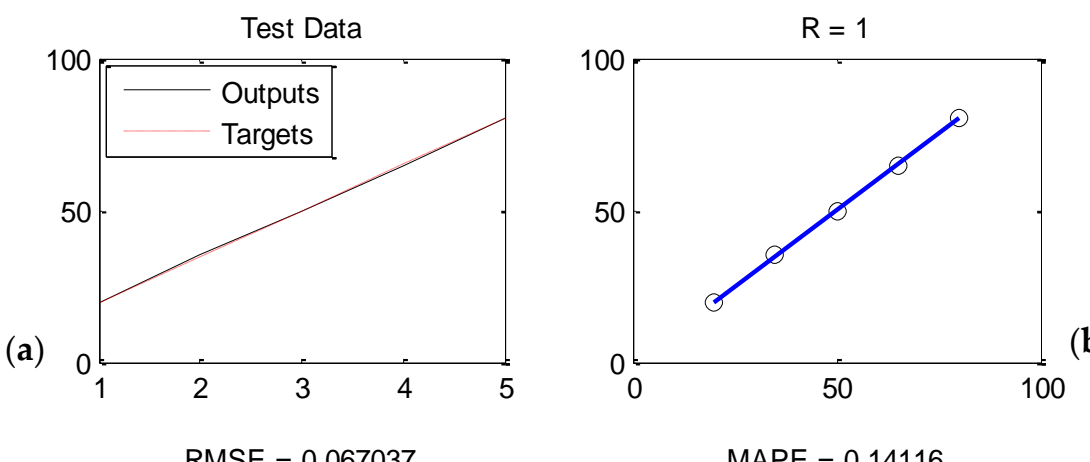

(b)
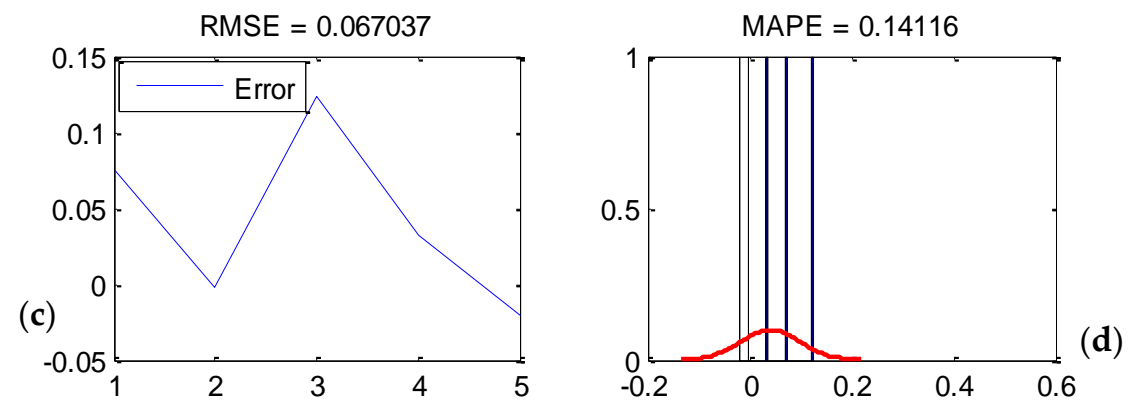

Figure 9. Regression diagram and comparison of real and measured data for test data in the optimum voltage: (a) comparison of real and measured data, (b) regression diagram, (c) obtained RMSE error, and (d) histogram of obtained error.

Usage of the X-Ray tube with a switch off/on as radiation source in flow meters has many advantages. It is safer than other systems and also can save money. To the best knowledge of the authors, there is no study in order to optimize the X-ray tube voltage in flow metering for improving the precision and efficiency. As can be seen in the Results section, a tube voltage of $225 \mathrm{kV}$ is the optimum voltage for the $\mathrm{X}$-ray tube and, in this condition, the precision of the metering system is more than higher and lower voltages.

\section{Conclusions}

In this paper, the voltage of the X-ray tube was optimized in order to increase the precision and efficiency of the X-ray radiation-based flow meters. This optimization study was performed in an annular two-phase flow. All the essential data in different tube voltages was obtained using MCNP-X code. Using MATLAB 8.1.0.604 software, a feature extraction method was performed on the output signals of the detector in every case, and the obtained matrixes were applied to the designed RBFNNs. The desired output of the networks was GVP. The precision of the networks in every voltage and every number of neurons in the hidden layer were obtained. The results show that $225 \mathrm{kV}$ tube voltage is the optimum voltage for this purpose. The obtained MAE error for this case is less than 0.05 , which shows the very high precision of the metering system with an optimum X-ray tube voltage.

Author Contributions: Conceptualization, S.M.A. and I.M.N.; methodology, A.K.A., K.S.N.; software, A.K.A.; investigation, K.S.N.; data curation, E.N.; writing-original draft preparation, S.M.A., J.W.G.G., E.E.-Z.; writing-review and editing, H.M.A.-D.; visualization, J.W.G.G.; supervision, E.N.; funding acquisition, I.M.N., A.K.A., E.E.-Z., K.S.N., H.M.A.-D. All authors have read and agreed to the published version of the manuscript.

Funding: We acknowledge support by the German Research Foundation and the Open Access Publication Fund of the Thueringer Universitaets- und Landesbibliothek Jena Projekt-Nr. 433052568. This work was supported by the Taif University Researchers Supporting Project grant number (TURSP-2020/266), of Taif University, Taif, Saudi Arabi. This paper has been supported by the RUDN University Strategic Academic Leadership Program. The research was performed at the expense of the subsidy for the state assignment in the field of scientific activity for 2021 No FSRW-2020-0014. 
Institutional Review Board Statement: Not applicable.

Informed Consent Statement: Not applicable.

Data Availability Statement: Data are contained within the article.

Conflicts of Interest: The authors declare no conflict of interest.

\section{References}

1. Almutairi, Z.; Al-Alweet, F.M.; Alghamdi, Y.A.; Almisned, O.A.; Alothman, O.Y. Investigating the characteristics of two-phase flow using electrical capacitance tomography (ECT) for three pipe orientations. Processes 2020, 8, 51. [CrossRef]

2. Yang, Y.; Wang, D.; Niu, P.; Liu, M.; Wang, S. Gas-liquid two-phase flow measurements by the electromagnetic flowmeter combined with a phase-isolation method. Flow Meas. Instrum. 2018, 60, 78-87. [CrossRef]

3. Wongsaroj, W.; Hamdani, A.; Thong-Un, N.; Takahashi, H.; Kikura, H. Extended short-time fourier transform for ultrasonic velocity profiler on two-phase bubbly flow using a single resonant frequency. Appl. Sci. 2019, 9, 50. [CrossRef]

4. Roshani, G.H.; Nazemi, E.; Feghhi, S.A.H. Investigation of using 60Co source and one detector for determining the flow regime and void fraction in gas-liquid two-phase flows. Flow Meas. Instrum. 2016, 50, 73-79. [CrossRef]

5. Roshani, M.; Phan, G.; Roshani, G.H.; Hanus, R.; Nazemi, B.; Corniani, E.; Nazemi, E. Combination of X-ray tube and GMDH neural network as a nondestructive and potential technique for measuring characteristics of gas-oil-water three phase flows. Measurement 2021, 168, 108427. [CrossRef]

6. Asano, H.; Takenaka, N.; Fujii, T. Flow characteristics of gas-liquid two-phase flow in plate heat exchanger: (Visualization and void fraction measurement by neutron radiography). Exp. Therm. Fluid Sci. 2004, 28, 223-230. [CrossRef]

7. Hewitt, G.F.; Roberts, D.N. Studies of Two-Phase Flow Patterns by Simultaneous X-Ray and Flast Photography; No. AERE-M-2159; Atomic Energy Research Establishment: Harwell, UK, 1969.

8. Jones, O.C., Jr.; Zuber, N. The interrelation between void fraction fluctuations and flow patterns in two-phase flow. Int. J. Multiph. Flow 1975, 2, 273-306. [CrossRef]

9. Harvel, G.D.; Hori, K.; Kawanishi, K.; Chang, J.S. Cross-sectional void fraction distribution measurements in a vertical annulus two-phase flow by high speed X-ray computed tomography and real-time neutron radiography techniques. Flow Meas. Instrum. 1999, 10, 259-266. [CrossRef]

10. Fischer, F.; Hampel, U. Ultra fast electron beam X-ray computed tomography for two-phase flow measurement. Nucl. Eng. Des. 2010, 240, 2254-2259. [CrossRef]

11. Song, K.; Liu, Y. A compact x-ray system for two-phase flow measurement. Meas. Sci. Technol. 2018, 29, 025305. [CrossRef]

12. Roshani, M.; Ali, P.J.M.; Roshani, G.H.; Nazemi, B.; Corniani, E.; Phan, N.H.; Tran, H.N.; Nazemi, E. X-ray tube with artificial neural network model as a promising alternative for radioisotope source in radiation based two phase flowmeters. Appl. Radiat. Isot. 2020, 164, 109255. [CrossRef]

13. Amiri, S.; Ali, P.J.M.; Mohammed, S.; Hanus, R.; Abdulkareem, L.; Alanezi, A.A.; Eftekhari-Zadeh, E.; Roshani, G.H.; Nazemi, E.; Kalmoun, E.M. Proposing a nondestructive and intelligent system for simultaneous determining flow regime and void fraction percentage of gas-liquid two phase flows using polychromatic X-ray transmission spectra. J. Nondestruct. Eval. 2021, 40, 1-12. [CrossRef]

14. Mäkiharju, S.A.; Gabillet, C.; Paik, B.G.; Chang, N.A.; Perlin, M.; Ceccio, S.L. Time-resolved two-dimensional X-ray densitometry of a two-phase flow downstream of a ventilated cavity. Exp. Fluids 2013, 54,1-21. [CrossRef]

15. Tekawade, A.; Sforzo, B.A.; Matusik, K.E.; Fezzaa, K.; Kastengren, A.L.; Powell, C.F. Time-resolved 3D imaging of two-phase fluid flow inside a steel fuel injector using synchrotron X-ray tomography. Sci. Rep. 2020, 10, 1-9.

16. Heindel, T.J. A review of X-ray flow visualization with applications to multiphase flows. J. Fluids Eng. 2011, $133,074001$. [CrossRef]

17. Pelowitz, D.B. MCNP-X TM User's Manual, Version 2.5.0. LA-CP-05e0369; Los Alamos National Laboratory: Los Alamos, NM, USA, 2005.

18. Karami, A.; Roshani, G.H.; Khazaei, A.; Nazemi, E.; Fallahi, M. Investigation of different sources in order to optimize the nuclear metering system of gas-oil-water annular flows. Neural Comput. Appl. 2020, 32, 3619-3631. [CrossRef]

19. Roshani, M.; Phan, G.T.; Ali, P.J.M.; Roshani, G.H.; Hanus, R.; Duong, T.; Corniani, E.; Nazemi, E.; Kalmoun, E.M. Evaluation of flow pattern recognition and void fraction measurement in two phase flow independent of oil pipeline's scale layer thickness. Alex. Eng. J. 2021, 60, 1955-1966. [CrossRef]

20. Salgado, C.M.; Pereira, C.M.; Schirru, R.; Brandão, L.E. Flow regime identification and volume fraction prediction in multiphase flows by means of gamma-ray attenuation and artificial neural networks. Prog. Nucl. Energy 2010, 52, 555-562. [CrossRef]

21. Nazemi, E.; Feghhi, S.; Roshani, G.; Setayeshi, S.A.; Peyvandi, R.G. A radiation-based hydrocarbon two-phase flow meter for estimating of phase fraction independent of liquid phase density in stratified regime. Flow Meas. Instrum. 2015, 46, 25-32. [CrossRef]

22. Nazemi, E.; Feghhi, S.; Roshani, G.; Peyvandi, R.G.; Setayeshi, S. Precise void fraction measurement in two-phase flows independent of the flow regime using gamma-ray attenuation. Nucl. Eng. Technol. 2016, 48, 64-71. [CrossRef]

23. Roshani, G.; Nazemi, E.; Roshani, M. Identification of flow regime and estimation of volume fraction independent of liquid phase density in gas-liquid two-phase flow. Prog. Nucl. Energy 2017, 98, 29-37. [CrossRef] 
24. Roshani, G.H.; Nazemi, E.; Roshani, M.M. Flow regime independent volume fraction estimation in three-phase flows using dual-energy broad beam technique and artificial neural network. Neural Comput. Appl. 2016, 28, 1265-1274. [CrossRef]

25. Buhmann, M.D. Radial Basis Functions: Theory and Implementations; Cambridge University: Cambridge, UK, 2003; ISBN 0-521-63338-9.

26. Aleksandrov, A.N.; Kishchenko, M.A.; Van, T.N. Simulating the formation of wax deposits in wells using electric submersible pumps. In Advances in Raw Material Industries for Sustainable Development Goals; CRC Press: London, UK, 2021; pp. 283-295. [CrossRef]

27. Khounani, Z.; Hosseinzadeh-Bandbafha, H.; Nazemi, F.; Shaeifi, M.; Karimi, K.; Tabatabaei, M.; Aghbashlo, M.; Lam, S.S. Exergy analysis of a whole-crop safflower biorefinery: A step towards reducing agricultural wastes in a sustainable manner. J. Environ. Manag. 2021, 279, 111822. [CrossRef] [PubMed]

28. Karpikov, A.V.; Aliev, R.I.; Babyr, N.V. An analysis of the effectiveness of hydraulic fracturing at YS1 of the Northern field. In IOP Conference Series: Materials, Science and Engineering; IOP Publishing: Bristol, UK, 2020; Volume 952, p. 012036.

29. Prischepa, O.M.; Nefedov, Y.V.; Kochneva, O.E. Raw material base of hard-to-extract oil reserves of Russia (Matéria-prima base de reservas de óleo de difícil extração da Rússia). Periodico TCHE Quimica 2020, 17, 915-924.

30. Roshani, S.; Roshani, S. Design of a high efficiency class-F power amplifier with large signal and small signal measurements. Measurement 2020, 149, 106991. [CrossRef]

31. Lalbakhsh, A.; Mohamadpour, G.; Roshani, S.; Ami, M.; Roshani, S.; Sayem, A.S.M.; Alibakhshikenari, M.; Koziel, S. Design of a compact planar transmission line for miniaturized rat-race coupler with harmonics suppression. IEEE Access 2021, 9 , 129207-129217. [CrossRef]

32. Pirasteh, A.; Roshani, S.; Roshani, S. A modified class-F power amplifier with miniaturized harmonic control circuit. AEU Int. J. Electron. Commun. 2018, 97, 202-209. [CrossRef]

33. Lalbakhsh, A.; Jamshidi, M. (Behdad); Siahkamari, H.; Ghaderi, A.; Golestanifar, A.; Linhart, R.; Talla, J.; Simorangkir, R.B.; Mandal, K. A compact lowpass filter for satellite communication systems based on transfer function analysis. AEU-Int. J. Electron. Commun. 2020, 124, 153318. [CrossRef]

34. Ruiz-Morales, B.; Espitia-Moreno, I.C.; Alfaro-Garcia, V.G.; Leon-Castro, E. Sustainable development goals Analysis with ordered weighted average operators. Sustainability 2021, 13, 5240. [CrossRef]

35. Lalbakhsh, A.; Afzal, M.U.; Hayat, T.; Esselle, K.P.; Manda, K. All-metal wideband metasurface for near-field transformation of medium-to-high gain electromagnetic sources. Sci. Rep. 2021, 11, 1-9.

36. Jamshidi, M.B.; Siahkamari, H.; Roshani, S.; Roshani, S. A compact Gysel power divider design using U-shaped and T-shaped reso-nators with harmonics suppression. Electromagnetics 2019, 39, 491-504. [CrossRef]

37. Lalbakhsh, A.; Alizadeh, S.M.; Ghaderi, A.; Golestanifar, A.; Mohamadzade, B.; Jamshidi, M.B.; Mandal, K.; Mohyuddin, W. A design of a dual-band bandpass filter based on modal analysis for modern communication systems. Electronics 2020, 9, 1770. [CrossRef]

38. Moradi, M.J.; Hariri-Ardebili, M.A. Developing a library of shear walls database and the neural network based predictive meta-model. Appl. Sci. 2019, 9, 2562. [CrossRef]

39. Nazemi, B.; Rafiean, M. Forecasting house prices in Iran using GMDH. Int. J. Hous. Mark. Anal. 2021, 14, 555-568. [CrossRef]

40. Nazemi, B.; Rafiean, M. Modelling the affecting factors of housing price using GMDH-type artificial neural networks in Isfa-han city of Iran. Int. J. Hous. Mark. Anal. 2021, 32, 3619-3631.

41. Roshani, G.H.; Feghhi, S.A.H.; Mahmoudi-Aznaveh, A.; Nazemi, E.; Adineh-Vand, A. Precise volume fraction prediction in oil-water-gas multiphase flows by means of gamma-ray attenuation and artificial neural networks using one detector. Meas. 2014, 51, 34-41. [CrossRef]

42. Ghanbari, B.; Yusuf, A.; Inc, M.; Baleanu, D. The new exact solitary wave solutions and stability analysis for the (2+1)-dimensional Zakharov-Kuznetsov equation. Adv. Differ. Equ. 2019, 2019, 1-15. [CrossRef]

43. Roshani, G.; Nazemi, E.; Roshani, M. Intelligent recognition of gas-oil-water three-phase flow regime and determination of volume fraction using radial basis function. Flow Meas. Instrum. 2017, 54, 39-45. [CrossRef]

44. Ghanbari, B. Abundant exact solutions to a generalized nonlinear Schrödinger equation with local fractional derivative. Math. Methods Appl. Sci. 2021, 44, 8759-8774. [CrossRef]

45. Roshani, G.H.; Roshani, S.; Nazemi, E.; Roshani, S. Online measuring density of oil products in annular regime of gas-liquid two phase flows. Measurement 2018, 129, 296-301. [CrossRef]

46. Ghanbari, B.; Nisar, K.S.; Aldhaifallah, M. Abundant solitary wave solutions to an extended nonlinear Schrödinger's equation with conformable derivative using an efficient integration method. Adv. Differ. Equ. 2020, 2020, 1-25. [CrossRef]

47. Karami, A.; Roshani, G.H.; Nazemi, E.; Roshani, S. Enhancing the performance of a dual-energy gamma ray based three-phase flow meter with the help of grey wolf optimization algorithm. Flow Meas. Instrum. 2018, 64, 164-172. [CrossRef]

48. Srivastava, H.M.; Günerhan, H.; Ghanbari, B. Exact traveling wave solutions for resonance nonlinear Schrödinger equation with intermodal dispersions and the Kerr law nonlinearity. Math. Methods Appl. Sci. 2019, 42, 7210-7221. [CrossRef]

49. Roshani, G.; Nazemi, E. Intelligent densitometry of petroleum products in stratified regime of two phase flows using gamma ray and neural network. Flow Meas. Instrum. 2017, 58, 6-11. [CrossRef] 
50. Roshani, M.; Phan, G.; Faraj, R.H.; Phan, N.H.; Roshani, G.H.; Nazemi, B.; Corniani, E.; Nazemi, E. Proposing a gamma radiation based intelligent system for simultaneous analyzing and detecting type and amount of petroleum by-products. Neural Eng. Technol. 2021, 53, 1277-1283. [CrossRef]

51. Golijanek-Jędrzejczyk, A.; Mrowiec, A.; Hanus, R.; Zych, M.; Heronimczak, M.; Świsulski, D. The assessment of metrological properties of segmental orifice based on simulations and experiments. Measurement 2021, 181, 109601. [CrossRef]

52. Roshani, G.H.; Nazemi, E.; Feghhi, S.A.; Setayeshi, S. Flow regime identification and void fraction prediction in two-phase flows based on gamma ray attenuation. Measurement 2015, 62, 25-32. [CrossRef]

53. Zych, M.; Petryka, L.; Kępiński, J.; Hanus, R.; Bujak, T.; Puskarczyk, E. Radioisotope investigations of compound two-phase flows in an open channel. Flow Meas. Instrum. 2014, 35, 11-15. [CrossRef]

54. Sattari, M.A.; Roshani, G.H.; Hanus, R.; Nazemi, E. Applicability of time-domain feature extraction methods and artificial intelligence in two-phase flow meters based on gamma-ray absorption technique. Measurement 2021, 168, 108474. [CrossRef]

55. Zych, M.; Hanus, R.; Wilk, B.; Petryka, L.; Świsulski, D. Comparison of noise reduction methods in radiometric correlation measurements of two-phase liquid-gas flows. Measurement 2018, 129, 288-295. [CrossRef]

56. Dolgii, I.E. Methods to enhance oil recovery in the process of complex field development of the Yarega oil and titanium deposit. J. Min. Inst. 2017, 231, 263-297.

57. Nguyen, V.T.; Rogachev, M.K.; Aleksandrov, A.N. A new approach to improving efficiency of gas-lift wells in the conditions of the formation of organic wax deposits in the dragon field. J. Pet. Explor. Prod. Technol. 2020, 10, 3663-3672. [CrossRef]

58. Sandyga, M.S.; Struchkov, I.A.; Rogachev, M.K. Formation damage induced by wax deposition: Laboratory investigations and modeling. J. Pet. Explor. Prod. Technol. 2020, 10, 2541-2558. [CrossRef]

59. Sultanbekov, R.; Islamov, S.; Mardashov, D.; Beloglazov, I.; Hemmingsen, T. Research of the influence of marine residual fuel composition on sedimentation due to incompatibility. J. Mar. Sci. Eng. 2021, 9, 1067. [CrossRef]

60. Roshani, G.; Nazemi, E.; Roshani, M. Usage of two transmitted detectors with optimized orientation in order to three phase flow me-tering. Measurement 2017, 100, 122-130. [CrossRef]

61. Kashnikov, Y.A.; Ashikhmin, S.G.; Kukhtinskii, A.E.; Shustov, D.V. The relationship of fracture toughness coefficients and geophysical characteristics of rocks of hydrocarbon deposits. J. Min. Inst. 2020, 1, 241. [CrossRef]

62. Belonogov, E.V.; Korovin, A.Y.; Yakovlev, A.A. Increase of the injectivity coefficient by dynamic development of injection wells. J. Min. Inst. 2019, 1, 238.

63. Grigorev, M.B.; Tananykhin, D.S.; Poroshin, M.A. Sand management approach for a field with high viscosity oil. J. Appl. Eng. Sci. 2020, 18, 64-69. [CrossRef]

64. Roshani, G.; Hanus, R.; Khazaei, A.; Zych, M.; Nazemi, E.; Mosorov, V. Density and velocity determination for single-phase flow based on radiotracer technique and neural networks. Flow Meas. Instrum. 2018, 61, 9-14. [CrossRef]

65. Shagiakhmetov, A.M.; Podoprigora, D.G.; Terleev, A.V. The study of the dependence of the rheological properties of gelforming compositions on the crack opening when modeling their flow on a rotational viscometer. Period. Tche Quimica 2020, 17, 933-939. [CrossRef]

66. Galkin, S.V.; Kochnev, A.A.; Zotikov, V.I. Predictive assessment of the effectiveness of radial drilling technology for the Bashkir production facilities of the Perm Territory fields. J. Min. Inst. 2019, 1, 238.

67. Molchanov, A.A.; Ageev, P.G. Implementation of new technologies is a reliable way of extracting residual reserves of hydrocarbon deposits. J. Min. Inst. 2017, 1, 227.

68. Morenov, V.; Leusheva, E.; Martel, A. Investigation of the fractional composition effect of the carbonate weighting agents on the rheology of the clayless drilling mud. Int. J. Eng. 2018, 31, 1152-1158. [CrossRef]

69. Nikitin, M.N.; Saychenko, L.A. The rheological properties of abnormally viscous oil. Pet. Sci. Technol. 2018, 36, 136-140. [CrossRef]

70. Francik, S.; Kurpaska, S. The use of artificial neural networks for forecasting of air temperature inside a heated foil tunnel. Sensors 2020, 20, 652. [CrossRef] [PubMed]

71. Francik, S.; Knapczyk, A.; Knapczyk, A.; Francik, R. Decision support system for the production of miscanthus and willow briquettes. Energies 2020, 13, 1364. [CrossRef]

72. Ghanbari, B. A new model for investigating the transmission of infectious diseases in a prey-predator system using a non-singular fractional derivative. Math. Methods Appl. Sci. 2021. Available online: https://onlinelibrary.wiley.com/doi/abs/10.1002/mma.74 12 (accessed on 16 April 2021). [CrossRef]

73. Nabti, A.; Ghanbari, B. Global stability analysis of a fractional SVEIR epidemic model. Math. Methods Appl. Sci. 2021, 44, 8577-8597. [CrossRef]

74. Ghanbari, B. On the modeling of the interaction between tumor growth and the immune system using some new fractional and fractional-fractal operators. Adv. Differ. Equ. 2020, 2020, 585. [CrossRef]

75. Djilali, S.; Ghanbari, B. The influence of an infectious disease on a prey-predator model equipped with a fractional-order derivative. Adv. Differ. Equ. 2021, 2021, 20. [CrossRef]

76. Wu, H.; Zhang, F.; Zhang, Z. Fundamental spray characteristics of air-assisted injection system using aviation kerosene. Fuel 2021, 286, 119420. [CrossRef]

77. Ghanbari, B. A fractional system of delay differential equation with nonsingular kernels in modeling hand-foot-mouth disease. Adv. Differ. Equ. 2020, 2020, 536. [CrossRef] [PubMed] 
78. Djilali, S.; Ghanbari, B. Dynamical behavior of two predators-one prey model with generalized functional response and time-fractional derivative. Adv. Differ. Equ. 2021, 2021, 1-19. [CrossRef]

79. Ghanbari, B. On novel nondifferentiable exact solutions to local fractional Gardner's equation using an effective technique. Math. Methods Appl. Sci. 2021, 44, 4673-4685. [CrossRef]

80. Ghanbari, B. On approximate solutions for a fractional prey-predator model involving the Atangana-Baleanu derivative. Adv. Differ. Equ. 2020, 2020, 679. [CrossRef]

81. Ghanbari, B.; Atangana, A. Some new edge detecting techniques based on fractional derivatives with non-local and non-singular kernels. Adv. Differ. Equ. 2020, 2020, 435. [CrossRef]

82. Ghanbari, B.; Inc, M.; Rada, L. Solitary wave solutions to the Tzitzéica type equations obtained by a new efficient approach. J. Appl. Anal. Comput. 2019, 9, 568-589. [CrossRef]

83. Rahman, G.; Nisar, K.S.; Ghanbari, B.; Abdeljawad, T. On generalized fractional integral inequalities for the monotone weighted Chebyshev functionals. Adv. Differ. Equ. 2020, 2020, 368. [CrossRef] 